\title{
Business Strategy and Leadership Style: Impact on Organizational Performance in the Manufacturing Sector of Ghana
}

\author{
John Parker Yanney \\ Department of Business Administration, Atlantic International University, Honolulu, Hawaii, USA \\ Email: parkerj964@gmail.com
}

Received 19 October 2014; revised 30 November 2014; accepted 16 December 2014

Copyright (C) 2014 by author and Scientific Research Publishing Inc.

This work is licensed under the Creative Commons Attribution International License (CC BY).

http://creativecommons.org/licenses/by/4.0/

c. (7) Open Access

\section{Abstract}

This study sought to investigate the impact of leadership styles and business strategy on the organizational performance of small medium scale enterprises (SMEs) in the manufacturing sector of Ghana. This had become necessary due to the fact that available literature on the subject matter lacked precision in terms of the specific leadership style and strategy which could better be employed to improve performance in the chosen area of study. A field survey (by means of questionnaires) was conducted in Accra, involving 60 CEOs and senior managers drawn from 10 organizations, which were randomly sampled for the study. In addition, a time series data from 2008 to 2013 on sales, profits before tax and employment from the 10 organizations were collected to develop performance indices for the organizations. Regression and analysis of variance (ANOVA) were then run to examine the relationship between leadership, strategy and organizational performance. The study revealed that leadership and business strategy statistically and significantly impacted on organizational performance but strategy had greater influence. Again, transformational leadership style and cost leadership significantly influenced organizational behaviour ( $p=$ $0.000<0.01$ ) but transactioanal leadership style, differentiation and focus strategies did not. The study recommends that SMEs should take advantage of transformational leadership style and cost leadership to enhance growth and induce greater organizational performance.

\section{Keywords}

Business Strategy, Leadership Style, Performance, Small Medium Scale Enterprises

\section{Introduction}

The impact of leadership and business strategy on organizational performance is a subject that has gained so 
much attention, particularly in this era of increasing globalization and market competition. Reference [1], for instance, is of the view that the leadership behaviors of the top management of small/medium-sized enterprises (SMEs) can have a strong impact on the performance and level of innovation of the firms; therefore, as the business becomes globally competitive, SMEs need to develop new sets of vision to sustain their businesses and to become more competitive. In this regard, the leadership behaviors of the business owner or manager play a major role in providing the needed direction and a clear vision, which must be shared by all the employees in the establishments [2].

As regards the leadership behaviors and performance of SMEs, transformational leadership is believed to have a positive impact on the performance of SMEs, a relationship which is found to be significant [1] [3]. However, the findings on how transactional leadership impacts on organizational performance appear contradictory. For example, whereas [1] found a significantly positive relationship (although small) between transactional leadership and the performance of SMEs, [3] discovered a significantly negative relationship between the same variables. In one of those studies also, [4] found that only the transformational leadership was the significant predictor of organizational performance but transactional leadership was not. Perhaps these differences in the findings could be accounted for by the research setting or the industry concerned.

It needs to be emphasized that, the performance of SMEs is also a product of strategy, in which the business owner or manager plays an important role in the formulation of the firm's strategy [5]. The owner/manager's competitive development and personal goals determine the understanding and use of strategic management and planning [6]. A meta-analysis of existing studies by [7] has indicated a positive linkage between strategy and growth. Reference [8] has also observed that strategy leads to superior and sustainable performance. As a result, when a company develops and implements effective long-term strategies, it could impact on the competitive positioning of that company on the market.

However, it must be emphasized that the role of business owners in the formulation and implementation of business strategies can have adverse impact on organizational performance in the absence of any mediating factors between strategy formulation, implementation, and organizational performance. What defines these mediating factors may depend on several considerations including the leadership style of the business owner, the extent to which other managers can influence the behavior of the business owners and the business environment generally among others.

\subsection{Defining the Problem}

The SME's in the manufacturing sector in Ghana are dominated by sole-proprietors, who make business decisions, based not on broad consultations, but rather on their personal inclinations and leadership behaviors which do not help the businesses to perform as expected, in some cases. Besides, most SMEs are busily engulfed with operational problems, which prevent them from devoting adequate time to quality leadership and strategic management issues. Thus, the business owners and managers place very little value on formal planning, strategic thinking and a developing long-term vision [10]. In the face of weak leadership and managerial capabilities, most SMEs do not survive after their second "anniversaries" [11].

This notwithstanding, not much has been studied on SMEs, as regards how they can take advantage of effective leadership styles and strategies to improve upon their performance for better growth.

This study is therefore sought to bridge that literature gap by investigating the impact of leadership behaviors and strategy on the performance of SMEs in the manufacturing sector of Ghana. In order to achieve this, the following specific objectives were pursued:

1) to examine the impact of leadership behaviors on the performance of SME's in the manufacturing sector;

2) to assess the relative contributions of transformational and transactional leadership styles to organizational performance;

3) to examine the impact of strategy on organizational performance;

4) to ascertain the contributions of the generic competitive strategies of cost leadership, differentiation and focus strategies to organizational performance;

5) to compare the relative importance of leadership and strategy to the performance of the SMEs.

\subsection{The Hypotheses}

The following hypotheses were formulated to guide the study: 
$\mathrm{H}_{0}=$ Leadership behaviors do not have any impact on the performance of SMEs in the manufacturing sector of Ghana.

$\mathrm{H}_{1}$ = Leadership behaviors have an impact on the performance of SMEs in the manufacturing sector of Ghana.

$\mathrm{H}_{0}=$ Transformational leadership style is not more significantly related to organizational performance than transactional leadership style.

$\mathrm{H}_{1}=$ Transformational leadership style is more significantly related to organizational performance than transactional leadership style.

$\mathrm{H}_{0}=$ Business strategy does not have any impact on the performance of SMEs in the manufacturing sector of Ghana.

$\mathrm{H}_{1}=$ Business strategy has an impact on the performance of SMEs in the manufacturing sector of Ghana.

$\mathrm{H}_{0}=$ Cost leadership, differentiation and focus strategies do not have any significant positive relationship with organizational performance.

$\mathrm{H}_{1}=$ Cost leadership, differentiation and focus strategies have significant positive relationship with organizational performance.

$\mathrm{H}_{0}=$ Leadership does not contribute more greatly to organizational performance of the SMEs than strategy.

$\mathrm{H}_{1}=$ Leadership contributes more greatly to organizational performance of the SMEs than strategy.

\section{Literature Review}

This section reviews literature on the subject matter, taking into consideration the key concepts of leadership and strategy, and their relationship with organizational performance.

\subsection{Leadership and Organizational Performance in Context}

Leadership has been defined in various ways by different authors. Reference [12] says leadership is an act of influencing people to cooperate towards the same goal which they come to find desirable. Reference [13] also defines leadership as a creation and maintenance of a sense of vision, culture, and interpersonal relationships, while [14] see leadership as working with and through people so as to accomplish goals. Leadership has also been distinguished from management which deals with coordinating activities, monitoring everyday operation of the organization and allocating resources and tasks to achieve organizational goals [13] [14].

According to [15], different leadership models, such as those of Bass [16] have been proposed, including transformational, transactional, and laissez-faire leadership styles, which come in addition to democratic and situational leadership styles. However, of interest to this study is the transformational and transactional leadership styles, as explained below.

Transformational leadership has been associated with the ability to rally people around, inspire vision, motivate followers to perform, and empower people to make change happen [17]. They attend to and treat individual employees by addressing their needs, listening attentively, furthering their development, advising and coaching them [16] [18]. On the other hand, transactional leadership motivates members through contingent reward or punishments based on compliance with set objectives and goals [19]. Thus, contingent reward, management by exception and laissez-faire are the key features of transactional leadership [20].

According to [21] [22], leadership is a determining factor of a firm's performance, and this has its roots in the literature [16] [23]. While agreeing that leadership styles affect organizational performance, [24] further state that transformational leadership has a positive relationship with organizational performance on some parameters, such as follower job performance, "group", performance, follower motivation and leader job performance but the laissez-faire component of transactional leadership recorded negative results, using the same parameters. Studies by other researchers have established such positive relationship between transformational leadership and organizational performance [20] [25].

\subsection{Strategy and Organizational Performance}

Reference [26] defines strategy in relation to the basic long-term organizational goals and the courses of action taken to achieve those goals, as well as allocating the resources required to carry out these goals. Reference [27] also define strategy with reference to the policies and key management decisions which are intended to have major impacts on the financial performance of an organization. According to [28], strategy is a process by which 
unique and valuable position is created, relying on a set of activities that are different from those of an organization's competitors. [29] also sees strategy as a plan, a ploy, a pattern, a position or a perspective, but in the opinion of [30], the plan or pattern should synchronize with an organization's major goals, policies and action sequences into a cohesive whole. The essence of having a strategy to provide value to customers and to gain competitive advantage [31].

Many different types of strategy have been proposed by different researchers, including intended and realized strategies, and their variants such as planned, entrepreneurial, ideological, umbrella, process, unconnected, consensus and imposed strategies [32]. References [28] [33] have also examined what has been termed the "generic strategies”. Reference [33] introduced four generic strategies, including the defender, the prospector, the analyzer and the reactor, while [28] developed three generic strategies, namely: cost leadership, differentiation and focus strategies. Cost leadership describes how a firm is set out to become a low-cost producer in its industry. Differentiation strategy refers to a firm seeking to be unique in its industry, and the focus strategy is important when a firm seeks to achieve competitive advantage in its target segment.

In Ghana, a study by [34] noted that majority of Ghanaian firms are adopting strategies which are akin to cost leadership. This allows them to offer products and services with features which are acceptable to many customer preferences. In this wise, the firms aim at building efficient scale facilities, using state-of-the-art manufacturing facilities, simplifying their processes, minimizing costs of sales, undertaking research and development and service, monitoring costs of activities provided by outsiders, and exercising tight control of production and overhead costs. In relation to differentiation strategy, [34] note that, an emerging economy like Ghana has low-consumer preference irrespective of product quality. Thus, there is over-reliance of imported goods, which makes the use of differentiation somehow unprofitable [35].

The relationship between strategy and performance has received much attention in the literature. Reference [7]'s meta-analysis of existing studies re-emphasized that there is a positive relationship between strategy and business growth. Reference [8] also established that strategy leads to superior organizational performance which is also sustainable. He noted that when a company develops and implements long-term strategies such as functional polices, it could earn positive advantage on the market. Thus, a firm's success is based on its strategy, to create and exploit conditions which give the firm unique competitive positioning.

In their study on performance of SMEs, [36] also found that strategy flexibility creates strengths and fasttrack niche-filling capabilities which in turn focus more on differentiation strategies. They note that differentiation strategies show positive performance in terms of innovation. Reference [37] also state that firms seeking to become more entrepreneurial must adopt differentiation strategies instead of cost leadership due to the nature of size. On the other hand, [10] was of the view that a growth strategy or differentiation has a positive impact on performance rather than cost leadership strategy.

However, a study on business strategy in Ghana by [38] reveals that cost leadership strategy results in improvements in efficiencies. These capabilities include cost and price reduction, increase in sales growth and market shares, and high performance.

\section{Methodology}

This study follows a quantitative and qualitative approach to data collection and analysis to examine the relationship between leadership, strategy and organizational performance, using SME's in the manufacturing sector in Ghana as the study area. Both primary data (by means of questionnaires) and time-series data (on sales, profits before tax and employment from (2008 to 2013) were collected and analyzed to determine the influences of leadership and strategy on organizational performance of the sampled SMEs. The performance measures used were the number of employees, sales and net profit before taxes. Transactional and transformational leadership styles were the measures used to determine their influences on performance. In relation to strategy, the measures were based on Porter's (1985) generic competitive strategy model, consisting of cost leadership, differentiation and focus strategy elements.

The population consisted of small and medium scale enterprises (SMEs) in the manufacturing sector, located within the industrial areas of Accra. In all, 641 active SMEs in the manufacturing sector were identified, out which of 10 (comprising 5 small scale and 5 medium scale organizations) were randomly sampled. From each of the 10 organizations, 6 workers were further selected randomly as respondents to the research instruments.

Multiple regression analysis models and paired sampled t-tests were used to test and analyze the hypotheses regarding the relationship between leadership styles, strategy and organizational performance by means of the 
statistical package for social scientists version 20 (SPSS 20). The equation models for the regression were specified as:

$$
O P=f(L s, S)
$$

where $O P=$ organizational performance; $L s=$ leadership style and $S=$ strategy.

$$
L s=f(\operatorname{Trs}, \operatorname{Tr} f)
$$

where $L s$ = leadership style; $\operatorname{Trs}=$ transactional leadership style; $\operatorname{Tr} f=$ transformational leadership style.

$$
S=f(C l, D, F s)
$$

where $S$ = strategy; $C l=$ cost leadership; $D=$ differentiation; $F s=$ focus strategy. Model was therefore specified as:

$$
O P=\alpha 0+\alpha 1 L s+\alpha 2 S+\mu
$$

where $\alpha 0$ is a constant, denoting the performance of small scale enterprises that is independent of the respective leadership styles, $\alpha 1, \alpha 2$ are model coefficients denoting the effect of the leadership behaviors and strategy on organizational performance, and $\mu$ is a random variable introduced to accommodate effect of other factors that affect organizational performance within or outside the leadership behaviors and strategy that are not included in the model.

\section{Findings and Discussion}

Table 1 shows the relationship between organizational performance as a dependent variable, and leadership style as an independent variable. The R square goodness of fit indicates that leadership style accounts for about $36 \%$ of the variations in organizational performance $\left(\mathrm{R}^{2}=359\right)$.

Table 2 shows that the relationship between organizational performance and leadership style is statistically significant $(0.000<p<0.01)$. The null hypothesis that leadership style does not have any impact on organizational performance of SMEs in the manufacturing sector of Ghana is thus rejected in favor of the alternate hypothesis.

Table 3 shows that the Pearson correlation between organizational performance and leadership style ispositive (Pearson correlation $=0.599)$ and that, this correlation is statistically significant $(0.000<p<0.01)$.

The above results confirm earlier studies on the subject matter carried out in Ghana and elsewhere [10] [34]. Similar studies by [16] found that leadership behavior affects organizational performance. The findings therefore support much of the findings established in earlier studies.

Table 4 shows that transformational and transactional leadership styles accounted for $82 \%$ of the variations in organizational performance of small and medium scale enterprises (SMEs) in the manufacturing sector of Ghana, holding all other factors constant. However, Table 5 indicates that whereas transformational leadership style

Table 1. Leadership regression model summary.

\begin{tabular}{|c|c|c|c|c|c|c|}
\hline & Model & Sum of squares & Df & Mean square & $\mathrm{F}$ & Significance \\
\hline \multirow{3}{*}{1} & Regression & 48.173 & 1 & 48.173 & 32.429 & $0.000^{\mathrm{b}}$ \\
\hline & Residual & 86.160 & 58 & 1.486 & & \\
\hline & Total & 134.333 & 59 & & & \\
\hline
\end{tabular}

\begin{tabular}{ccccc}
\hline Model & $\mathrm{R}$ & $\mathrm{R}$ square & Adjusted R square & Std. error of the estimate \\
\hline 1 & 0.599 & 0.359 & 0.348 & 1.219 \\
\hline
\end{tabular}

${ }^{\text {a }}$ Predictors: (constant), leadership.

Table 2. Analysis of variance between organizational performance and leadership.

${ }^{\mathrm{a}}$ Dependent variable: organizational performance; ${ }^{\mathrm{b}}$ Predictors: (constant), leadership.

Table 3. Pearson correlation between organizational performance and leadership style.

\begin{tabular}{cccc}
\hline & & Correlation & Significance \\
\hline Pair 1 & Organizational performance and leadership style & 0.599 & 0.000 \\
\hline
\end{tabular}


Table 4. Leadership regression model summary.

\begin{tabular}{ccccc}
\hline Model & $\mathrm{R}$ & $\mathrm{R}$ square & Adjusted R square & Std. error of the estimate \\
\hline 1 & 0.599 & 0.359 & 0.348 & 1.219 \\
\hline
\end{tabular}

${ }^{\mathrm{a}}$ Predictors: (constant), leadership.

Table 5. Coefficients ${ }^{\mathrm{a}}$ of transformational and transactional leadership styles.

\begin{tabular}{|c|c|c|c|c|c|c|}
\hline & \multirow{2}{*}{ Model } & \multicolumn{2}{|c|}{ Unstandardized coefficients } & \multirow{2}{*}{$\begin{array}{c}\text { Standardized coefficients } \\
\text { Beta }\end{array}$} & \multirow{2}{*}{$\mathrm{t}$} & \multirow{2}{*}{ Significance } \\
\hline & & B & Standard error & & & \\
\hline \multirow{3}{*}{1} & (Constant) & 2.438 & 0.310 & & 7.853 & 0.000 \\
\hline & Transformational & 0.843 & 0.054 & 0.893 & 15.745 & 0.000 \\
\hline & Transactional & 0.068 & 0.054 & 0.071 & 1.257 & 0.214 \\
\hline
\end{tabular}

${ }^{\mathrm{a}}$ Dependent variable: organizational performance.

statistically and significantly influences organizational performance $(p=0.000<0.001)$, transactional leadership was not statistically significant ( $p=0.214$ ) which is greater than 0.05 .

These findings confirm similar result by [20] who found that transformational leadership has a stronger relationship with organizational performance than transactional leadership, but it contradicts recent studies by [23] whose results indicated that performance is highly positively influenced by transactional leadership behavior, and therefore recommended transactional leadership style for small scale enterprises.

Table 6 also indicates that there is a statistically significant relationship between strategy and organizational performance $(p=0.000)$, and that strategy accounts for about $30.6 \%$ in the variations in organizational performance $\left(\mathrm{R}^{2}=0.306\right)$, as indicated on Table 7 .

Due to the significant relationship between organizational performance and strategy, the null hypothesis is rejected in favor of the alternate hypothesis. This confirms [7] [28] who also found that an effective strategy leads to superior and sustainable performance. The findings therefore are in sync with earlier findings and literature.

As indicated on Table 8, with exception of cost leadership, which has a statistically significant relationship with organizational performance $(0.000<p<0.01)$, differentiation and focus strategies were not statistically significant ( $p=0.396$ and 0.890 respectively).

Based on the result, the null hypothesis is partly accepted in respect of cost leadership, but rejected in relation to differentiation and focus strategies. The findings contradict [7] [30] who found positive relationships between differentiation strategy and focus strategy on one hand, and organizational performance on the other.

There was a statistically significant correlation between strategy and leadership $(033<p<0.05$; Pearson correlation $=0.276$ ), as indicated on Table 9 .

Although the correlation is positive, it is not very strong, due to the fact that 0.276 is far from 1 . Table 10 compares the means of strategy and leadership style.

The result indicates that, strategy has a higher mean (7.18) than leadership (5.12), meaning that strategy influences organizational performance more greatly than leadership. As a result, the null hypothesis is accepted. That notwithstanding, Table 11 shows that both strategy and leadership style influence organizational behavior by about $53 \%$ ( $\mathrm{R}$ square $=0.530,0.000<p<0.01)$.

The literature so far, had not assessed the combined impact of leadership and strategy on organizational performance together. Each variable has been tested as stand-alone. However, there is every reason to believe that if an organization has a good leadership, they are likely to develop good strategies to influence organizational performance. This aspect of the situation has been considered in part in earlier studies [7] [10] [37].

\section{Conclusion and Recommendations}

This study has examined the effect of leadership styles and strategy on organizational performance in small scale enterprises in the manufacturing sector of Ghana. The analysis has shown that both leadership and strategy play a key role in influencing organizational performance of the SMEs. However, whereas transformational leadership style has a significantly positive effect on organizational performance, transactional leadership style does not. 
Table 6. Analysis of variance between organizational performance and leadership.

\begin{tabular}{ccccccc}
\hline & Model & Sum of squares & Df & Mean square & F & Significance \\
\hline & Regression & 42.651 & 1 & 42.651 & 26.982 & $0.000^{\mathrm{b}}$ \\
1 & Residual & 91.683 & 58 & 1.581 & & \\
& Total & 134.333 & 59 & &
\end{tabular}

${ }^{\mathrm{a} D e p e n d e n t ~ v a r i a b l e: ~ o r g a n i z a t i o n a l ~ p e r f o r m a n c e . ~}{ }^{\mathrm{b}}$ Predictors: (constant), leadership.

Table 7. Regression model summary for strategy.

\begin{tabular}{ccccc}
\hline Model & $\mathrm{R}$ & $\mathrm{R}$ square & Adjusted R square & Std. error of the estimate \\
\hline 1 & $0.563^{\mathrm{a}}$ & 0.317 & 0.306 & 1.257 \\
\hline
\end{tabular}

${ }^{a}$ Predictors: (constant), strategy.

Table 8. Coefficients ${ }^{\mathrm{a}}$ of the generic competitive strategies.

\begin{tabular}{|c|c|c|c|c|c|}
\hline \multirow{2}{*}{ Model } & \multicolumn{2}{|c|}{ Unstandardized coefficients } & \multirow{2}{*}{$\begin{array}{c}\text { Standardized coefficients } \\
\text { Beta }\end{array}$} & \multirow{2}{*}{$\mathrm{t}$} & \multirow{2}{*}{ Significance } \\
\hline & B & Standard error & & & \\
\hline 1. (Constant) & 4.936 & 1.077 & & 4.581 & 0.000 \\
\hline Cost leadership & 0.466 & 0.087 & 0.893 & 5.352 & 0.000 \\
\hline Differentiation strategy & 0.036 & 0.260 & 0.015 & 0.139 & 0.890 \\
\hline Focus strategy & -0.145 & 0.170 & -0.094 & -0.855 & 0.396 \\
\hline
\end{tabular}

${ }^{\mathrm{a}}$ Dependent variable: organizational performance.

Table 9. Pearson correlation between leadership style and strategy.

\begin{tabular}{cccc}
\hline & & Correlation & Significance \\
\hline Pair 1 & Strategy and leadership style & 0.276 & 0.033 \\
\hline
\end{tabular}

Table 10. Comparison of the means between strategy and leadership style.

\begin{tabular}{ccccc}
\hline & & Mean & Standard deviation & Standard error mean \\
\hline \multirow{2}{*}{ Pair 1 } & Strategy & 7.18 & 1.432 & 0.185 \\
& Leadership style & 5.12 & 1.748 & 0.226 \\
\hline
\end{tabular}

Table 11. The extent to which combined strategy and leadership style influence organizational performance.

\begin{tabular}{ccccc}
\hline Model & $\mathrm{R}$ & R square & Adjusted R square & Std. error of the estimate \\
\hline 1 & $0.728^{\mathrm{a}}$ & 0.530 & 0.514 & 1.052
\end{tabular}

${ }^{\mathrm{a}}$ Predictors: (constant), strategy, leadership style; ${ }^{\mathrm{b}}$ Dependent variable: organizational performance.

Similarly, whereas cost leadership strategy exerts positive and significant effect on organizational performance, focus strategy and differentiation strategy do not have the same effect. However, the fact that leadership and strategy together account for $53 \%$ (all other factors held constant) is an indication that other factors account for $47 \%$ of organizational performance, thus making it pertinent for these other factors to be clearly established.

It is however recommended that the SMEs should capitalize on the use of transformational leadership style for a more sustained and effective growth, through effective training and development of their employees. In addition, the key elements of cost leadership strategies should be more effectively incorporated in the operations of the SMEs, through research and development. 


\section{Limitation and Implication for Future Research}

The data on leadership and strategy were collected only from the owners/top managers of the SMEs, meaning that the respondents could overate their leadership effectiveness. It would therefore be appropriate to conduct a cross-sectional empirical research which will include other respondents within each organization.

Again, the study concentrated on the manufacturing sector. As a result, the findings cannot be generalized for all the SMEs in Ghana. A similar assessment in SMEs in other sectors in the future will be appropriate.

However, any further studies on this subject may have to examine the other factors which also influence organizational performance, apart from leadership and strategy.

\section{References}

[1] Matzler, K., Schwarz, E., Deutinger, N. and Harms, R. (2008) Relationship between Transformational Leadership, Product Innovation and Performance in SMEs. Journal of Small Business and Entrepreneurship, 21, 139-152. ttp://dx.doi.org/10.1080/08276331.2008.10593418

[2] Yang, C.W. (2008) The Relationships among Leadership Styles, Entrepreneurial Orientation, and Business Performance. Managing Global Transitions, 6, 257-275.

[3] Pedraja, R.L., Emilio, R.P., Delgado, A.M. and Juan, R.P. (2006) Transformational and Transactional Leadership: A Study of their Influence in Small Companies. Ingeniare-Revista Chilena De Ingenieria, 14, 159-166.

[4] Yang, L., Zeki, S., Lubatkin, M.H. and Veigo, J. (2008) The Impact of Transformational CEO on the Performance of Small Medium Scale Size Firms: Does Organization Context Matter? Journal of Applied Psychology, 93, 923-934.

[5] Philipsen, R.L.C. and Kemp, R.G.M. (2003) Capabilities for Growth: An Exploratory Study on Medium-Sized Firms in the Dutch ICT Services and Life Sciences. EIM, Zoetermeer, 137.

[6] Postma, T.J.B.M. and Zwart, P.S. (2001) Strategic Research and Performance of SMEs. Journal of Small Business Strategy, 12, 52-64.

[7] Schwenk, C.R. and Shrader, C.B. (1993) The Effects of Formal Strategic Planning on Financial Performance in Small Firms: A Meta-Analysis. Entrepreneurship in Theory and Practice, 17, 53-64.

[8] Porter, M.E. (1991) Towards a Dynamic Theory of Strategy. Strategic Management Journal, 12, 95-117. http://dx.doi.org/10.1002/smj.4250121008

[9] Hanlon, D. and Scott, M.G. (1993) Strategy Formation in the Entrepreneurial Small Firm. Scottish Enterprise Foundation (SEF), Stirling.

[10] Pelham, A.M. (2000) Market Orientation and other Potential Influences on Performance in Small and Medium-Sized Manufacturing Firms. Journal of Small Business Management, 38, 48-67.

[11] Kayanula, D. and Quartey, P. (2000) The Policy Environment for Promoting Small and Medium-Sized Enterprises in Ghana and Malawi. Institute for Development Policy and Management, University of Manchester, Manchester, Working Series Paper 15. www.devinit.org/findev/Fd-wp15

[12] Tead, O. (1935) The Art of Leadership. McGraw Hill, New York.

[13] Day, C. (2000) Beyond Transformational Leadership. Educational Leadership, 57, 56-59.

[14] Hersey, P. and Blanchard, K.H. (1969) Management of Organizational Behavior: Utilizing Human Resources. Prentice Hall, New Jersey.

[15] Von Gelderen, M., Frese, M. and Thurik, R. (2000) Strategies, Uncertainty and Performance of Small Business Startups. Small Business Economics, 15, 165-181. http://dx.doi.org/10.1023/A:1008113613597

[16] Bass, B.M. (1985) Leadership: Good, Better, Best. Organizational Dynamics, 13, 26-40.

[17] Bromley, H.R. and Kirschiner-Bromley, V.A. (2007) Are You a Transformational Leader? Physician Executive, 33, 54-57.

[18] Thomas, A.B. (1988) Does Leadership Make a Difference to Organizational Performance? Administrative Science Quarterly, 33, 388-400. http://dx.doi.org/10.2307/2392715

[19] Burns, J.M. (1978) Leadership. Harper and Row, New York.

[20] Avolio, B.J. and Bass, B.M. (2001) Developing Potential across a Full Range of Leadership: Cases on Transactional and Transformational Leadership. Psychology Press, London.

[21] Boyatzis, R.E. (1982) The Competent Manager: A Model for Effective Performance. John Wiley and Sons, Inc., New York.

[22] Kirkpatrick, S.A. and Locke, E.A. (1991) Leadership: Do Traits Matter? Academy of Management Executive, 5, 48-60. 
[23] Brown, L. and Posner, B. (2001) Exploring the Relationship between Learning and Leadership. Leadership \& Organization Development Journal, 22, 274-280. http://dx.doi.org/10.1108/01437730110403204

[24] Mendl, J., Ehrlich, S. and Dukerich, J. (1985) The Romance of Leadership. Administrative Science Quarterly, 30, 78-102. http://dx.doi.org/10.2307/2392813

[25] Avolio, B.J. and Bass, B.M. (1995) Individual Consideration Viewed at Multiple Levels of Analysis: A Multi-Level Framework for Examining the Diffusion of Transformational Leadership. Leadership Quarterly, 6, 199-218. http://dx.doi.org/10.1016/1048-9843(95)90035-7

[26] Chandler, A.D. (1962) Strategy and Structure. MIT Press, Cambridge.

[27] Buzzell, R.D. and Gale, B.T. (1987) The PIMS Principles: Linking Strategy and Performance. Free Press, New York.

[28] Porter, M.E. (1980) Competitive Strategy: Techniques for Analyzing Industries and Competitors. Free Press, New York.

[29] Mintzberg, H. (1973) Strategy-Making in Three Modes. California Management Review, 16, 44-53. http://dx.doi.org/10.2307/41164491

[30] Seth, A. and Thomas, H. (1994) Theories of the Firm: Implications for Strategy Research. Journal of Management Studies, 31, 165-192. http://dx.doi.org/10.1111/j.1467-6486.1994.tb00770.x

[31] Hart, S.L. (1992) An Integrative Framework for Strategy-Making Process. Academy of Management Review, 17, 327351.

[32] Mintzberg, H. and Waters, J.A. (1985) Of Strategies: Deliberate and Emergent. Strategic Management Journal, 6, 257-272. http://dx.doi.org/10.1002/smj.4250060306

[33] Miles, R.E. and Snow, C.C. (1978) Organizational Strategy, Structure, and Process. McGraw-Hill, New York.

[34] Acquaah, A. and Ardekani, M.Y. (2008) Does the Implementation of a Combination of Competitive Strategies Yield Incremental Performance Benefits? A New Perspective from a Transition Economy in Sub-Saharan Africa. Journal of Business Research, 61, 346-354. http://dx.doi.org/10.1016/j.jbusres.2007.06.021

[35] Amoako-Gyampah, K. and Acquaah, M. (2008) Manufacturing Strategy, Competitive Strategy and Firm Performance: An Empirical Study in a Developing Economy Environment. International Journal of Production Economics, 111, 575-592. http://dx.doi.org/10.1016/j.ijpe.2007.02.030

[36] Fletcher, M. and Harris, S. (2002) Seven Aspects of Strategy Formation: Exploring the Value of Planning. International Small Business Journal, 20, 297-314. http://dx.doi.org/10.1177/0266242602203004

[37] Dess, G.G. and Davis, P.S. (1984) Porter’s (1980) Generic Strategies as Determinants of Strategic Group Membership and Organizational Performance. Academy of Management Journal, 27, 467-488. http://dx.doi.org/10.2307/256040

[38] Acquaah, M. (2011) Business Strategy and Competitive Advantage in Family Businesses in Ghana: The Role of Social Networking Relationships. Journal of Developmental Entrepreneurship, 16, 103-126. http://dx.doi.org/10.1142/S1084946711001744 
Scientific Research Publishing (SCIRP) is one of the largest Open Access journal publishers. It is currently publishing more than 200 open access, online, peer-reviewed journals covering a wide range of academic disciplines. SCIRP serves the worldwide academic communities and contributes to the progress and application of science with its publication.

Other selected journals from SCIRP are listed as below. Submit your manuscript to us via either submit@scirp.org or Online Submission Portal.
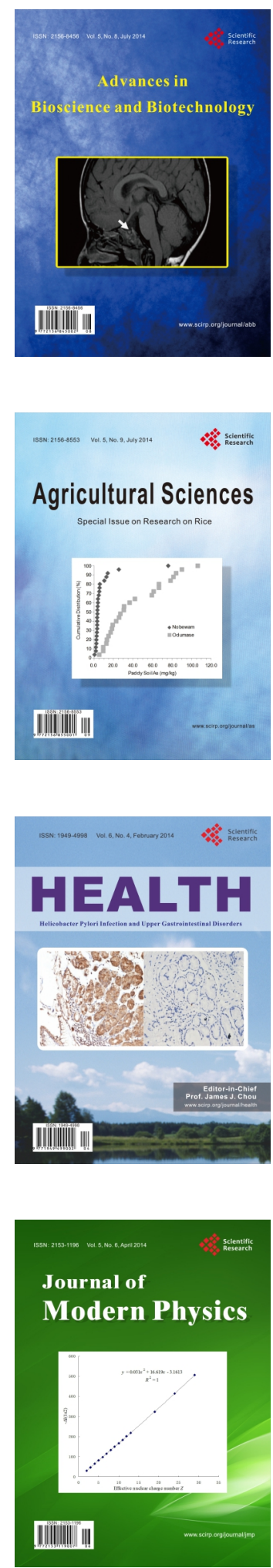
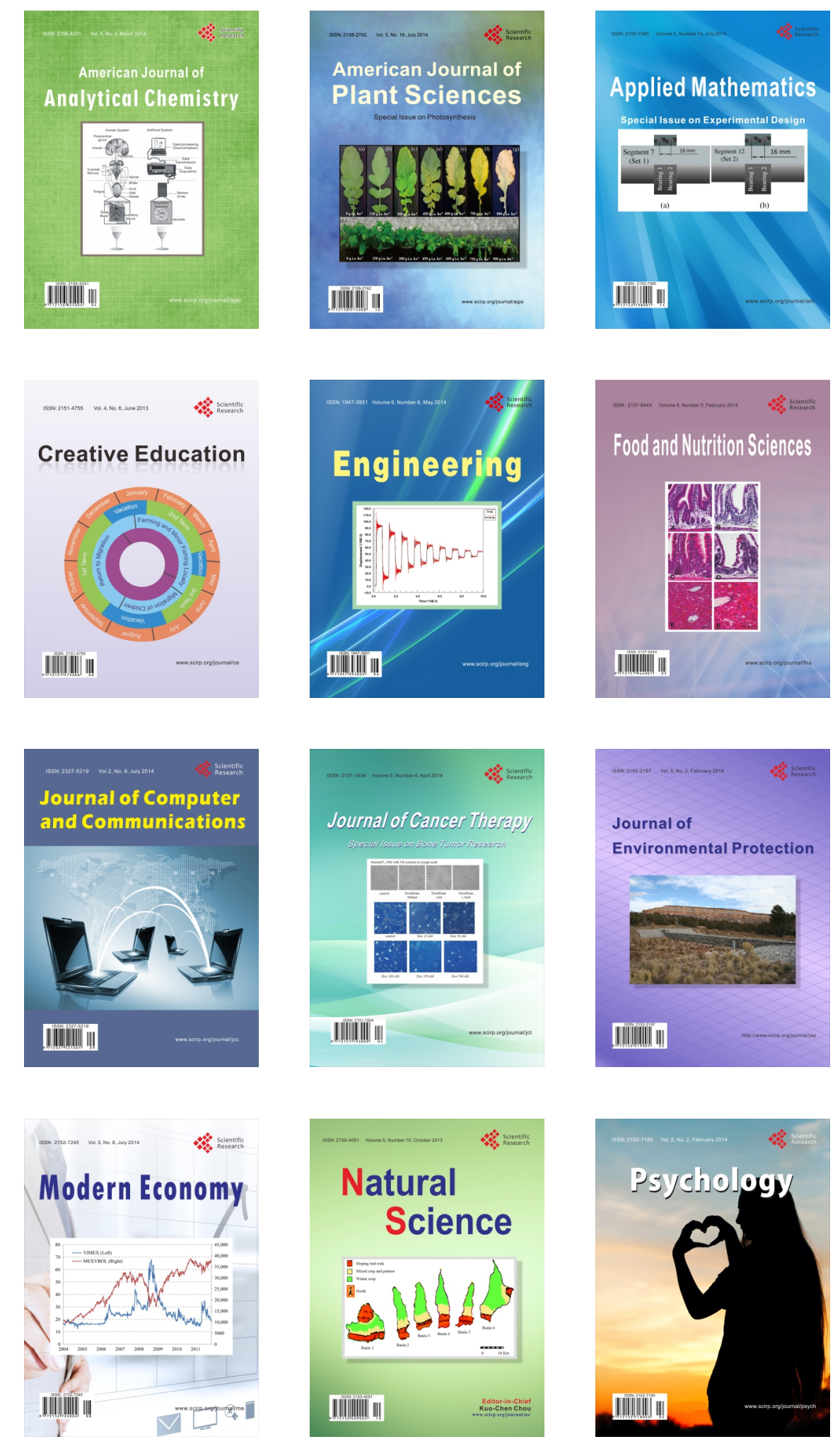